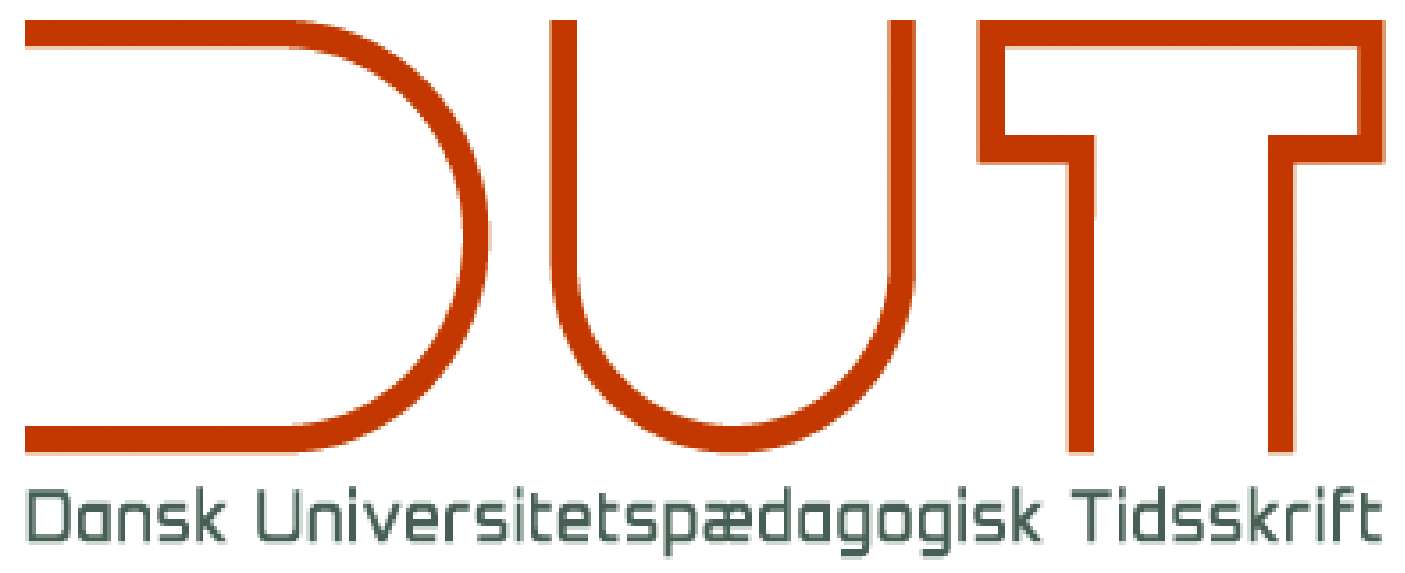

Universitetspædagogikum

Årgang 13 nr. 25 / 2018

Titel

Peer feedback among international PhD students

Forfatter

Sofie Kobayashi

Sidetal

$91-106$

Udgivet af

Dansk Universitetspædagogisk Netværk, DUN

URL

> http://dun-net.dk/

Betingelser for brug af denne artikel

(C) Copyright
Denne artikel er omfattet af ophavsretsloven, og der må citeres fra den. Følgende betingelser skal dog være opfyldt:

- Citatet skal være i overensstemmelse med "god skik"

- Der må kun citeres „i det omfang, som betinges af formålet“

- Ophavsmanden til teksten skal krediteres, og kilden skal angives ift. ovenstående bibliografiske oplysninger.

DUT og artiklens forfatter 


\section{Peer feedback among international PhD students}

Sofie Kobayashi, Assistant Professor, Department of Science Education, University of Copenhagen.

\section{Research article, peer-reviewed}

In a PhD course for new PhD students peer feedback was introduced to reduce teacher time on feedback and to enhance the learning environment. The results of the changes to the course are not conclusive with regards to teacher time, since there were also other changes made to the programme, but overall teacher time on giving feedback has been reduced. Peer feedback in higher education is seen as one way to enhance the learning environment for students as it builds on principles of formative feedback during the course of study and when students give feedback it has been shown to enhance learning. The results from this study support this view, but improved learning was only observed after peer feedback was integrated in teaching and learning activities embedded in the course rather than as an add-on.

This article describes and evaluates the introduction of an element of peer feedback in a PhD course. Peer feedback was introduced with the double goal of saving teacher time and enhancing learning outcomes. The changes made to the course were initiated as a development and learning project undertaken as part of my participation in the Teaching and Learning in Higher Education Programme (Universitetspaedagogikum) in 2016. The aim of the article is to share experiences that indicate that this double goal is achievable when a) assessment (or feedback) criteria are explicit and shared and b) peer feedback is an integral part of the course.

\section{Problem statement and intervention design}

The PhD course in question is the Introduction course for new PhD students at the University of Copenhagen, Faculty of Science, a five days' intensive residential course, off campus that was initiated in 2007. The participants submit two assignments, one is an essay on Responsible Conduct of Research and the other is a Personal Development Plan (PDP).

Initiating problem

As course responsible I have been asked to cut the time that course teachers spend on this course, for the department to generate an overhead to fund research. As the feedback on assignments is time consuming, this is an obvious place to cut teacher time. 
Financial sustainability was the trigger to consider peer feedback on PDP assignments. Although, the PDP submission is quite a specific circumstance, it was recognized that the study's findings would be of interest more broadly in academia since there is widespread concern about the amount of time that higher education tutors spend giving feedback to students. However, there is also widespread understanding that any alternative should not compromise the quality of teaching and learning. For instance Boud and Molloy (2013, p. 703) state that: 'The practical dilemma of higher education is that the amount and type of feedback that can realistically be given is severely limited by resource constraints...'

The problem of cutting teacher time becomes complex when considering how to maintain the quality of teaching and learning. However, peer feedback is an option, since this has been shown to have advantages in terms of enhancing learning, and there are a number of studies that indicate that both the one providing feedback and the receiver learn from the peer feedback process, e.g. Althauser and Darnall (2001); Cho and Cho (2011); Li, Liu and Steckelberg (2010). In general, teachers find that giving feedback is particularly time consuming when a submitted assignment leaves a lot of room for improvement. For the course that forms the basis of this study, there are usually one or two participants who seem lost, do not ask for help and submit very meager assignments. Through peer feedback help will be 'forced' on them, and they get to see other PDPs and can learn from their peers. Further, the process of giving feedback will help them understand the concept of the PDP and the criteria for a good assignment, and this will help them build capacities in selfassessment and self-regulation for their own future competence development. Hence, by giving feedback to their peers, it is our hope that all course participants will grasp the ideas of the PDP and submit good assignments. This will ease the effort needed for teacher feedback as it is the lower quality assignments that are most demanding to assess and comment on.

\section{Challenge}

The challenge that this project sets out to address is to both increase financial sustainability and enhance the learning environment through the use of peer feedback on assignments, and if possible to identify some conditions for this achievement.

\section{Context}

From the inception of the course, teachers have provided feedback to course participants on their PDP assignments. The aim was to provide formative feedback in the spirit of helping them to think further and encourage them to use the PDP for the annual Performance and Development Review (MUS) and Progress Assessment Reports. The PDP assignment is designed to support the Intended Learning Outcomes 
(ILOs) of the course. The most relevant ILOs in relation to the assessment of the effects of peer feedback on PDP assignments are outlined below:

- To position you to take charge of your PhD studies

- To take steps to co-manage the working relationship with your supervisor(s)

- To be able to navigate the personal / individual aspects of your PhD studies (e.g. work/life balance, motivation, stress)

The course activities and the PDP assignment urge participants to think about their present competencies, their career plans and goals, and make plans for competence development throughout their PhD. The PDP also includes sections on work-life balance, networking and collaboration with supervisors.

The first ILO, taking charge, is linked to Self-Determination Theory (SDT) and is an underlying premise of the course. According to Ryan and Deci (2000) autonomy plays an important role in building motivation, on a par with feeling competent and related. PhD students who feel that the supervisor is the sole or main decisionmaker may be at higher risk of losing their motivation. Such expectations are more common among PhD students from educational environments where it is the norm to listen to the teacher and do as told, and as such it is more common among some sections of international PhD students (Elliot \& Kobayashi, 2017). Danish supervisors expect PhD students to be quite autonomous from the outset, and hence 'taking charge' can also help align expectations in the supervisory relationship. One supervisor wrote of her two PhD students from an African country: 'They had been coached to take ownership of their own PhD project, which came out very prominently in successive supervision meetings'.

One objective we strive for under the first ILO, taking charge, is to raise awareness about the kinds of feedback participants might get from peers and supervisors as a way to develop their competencies throughout their PhD. We do this through a session about feedback, and we discuss specific vs. general feedback, the idea of constructive feedback and during the last year also formative and summative feedback (Black \& Wiliam, 2009). The main goal is to equip participants to discuss their expectations for feedback with their supervisors, and we aim to achieve this by having them work with feedback themselves. Here we take the constructivist view of learning for granted; that learning is enhanced through active engagement. I find the social constructivism meaningful in this context (Dolin, 2015; Dysthe, 1995), as interaction and communication about feedback enables the participants to ascribe meaning to different types of feedback and how feedback can enhance the learning process.

Furthermore, it is very important for a good PhD process to be able to ask for help, including feedback, and hence also to be able to give feedback to others for reciproc- 
ity. It falls under the concept of relational agency, which has been defined by Edwards and D'arcy (2004, p. 149) as the 'ability to seek out and use others as resources for action and equally to be able to respond to the need for support from others'. The relevance for doctoral education has been established by e.g. Hopwood (2010). Giving and receiving feedback thus supports the main ILO of the course, taking charge of PhD studies.

\section{Feedback and assessment}

In its simplest form feedback is a piece of information, written or oral, given to students, almost synonymous with telling students how well they did (summative feedback) or what to do next (formative feedback). This builds on the assumption that if only students do as they are told, they will improve their performance. Boud and Molloy (2013) question whether this is actually feedback, or only information, and they continue discussing the feedback loop; 'The cycle needs to be completed. If there is no discernable effect, then feedback has not occurred' (p. 702). A discernable effect requires an assessment of student performance in two subsequent tasks, first an assessment of competencies in one task, and a subsequent task in which the student can demonstrate their learning. Hence, they add a step to the framework of Hattie and Timperley (2007) where feedback is the assessment of a first task, feed up is setting (reachable) goals for development and identifying the gap and feed forward is the steps needed to close the gap. Boud and Molloy (2013) emphasise that feedback 'needs to be conceptualized as an explicit part of the design of the course or programme' (p. 702), and hence not just an add-on. Peer feedback requires training, and this is a point that I will revisit in the discussion.

Setting reachable goals during feed-up (Hattie \& Timperley, 2007) refers to Vygotsky's concept of the Proximal Zone of Development (PZD) (Dysthe, 1995; Vygotsky, 1978) and what Ryan and Deci (2000) frame as an 'optimal challenge' for a person to feel competent and thus build motivation and self-efficacy beliefs. If the goals are too high, the gap becomes too wide for the learner to fill. The consequence is that feedback needs to be balanced for the learner to find it meaningful to engage with the challenge. In the PZD learners can succeed when getting help from adults/ teachers/ more experienced others. The wider the gap, the more help is required for the learner to succeed. This is referred to as scaffolding, and engaging in dialogue with others is a fundamental aspect of scaffolding (Dysthe, 1995). Topping (2010) mentions other means of scaffolding, such as guiding prompts, sentence openers and cue cards.

It should be clear from the above that feedback is not possible without assessment. Assessing the quality of a product or the competencies of a student is necessary in order to facilitate further learning. In the introduction I stated that we provide 'formative feedback' with the aim that the participants can use the PDP in further compe- 
tence development throughout their PhD studies. The consequence of working with the proximal zone of development is that students will not get the same level of feedback, but each student will get feedback that can help them develop from the specific level they are at, to a desired and achievable higher level. This will not be the same for all students. Teachers will assess the students' levels and learning needs, and give each student individual feedback on that basis, and hence the validity of the feedback will be high for each individual student.

The use of the term 'formative feedback' implies that the purpose of the feedback is to support further learning and development. The formative - summative divide seems quite clear at first glance; formative feedback is feedback for learning while summative feedback is feedback of learning. However, even summative assessment, the assessment of learning outcomes, can be used formatively when students are involved in the process. The concept of formative assessment as defined by Black and Wiliam (2010) closes the feedback loop: 'We use the general term assessment to refer to all those activities undertaken by teachers - and by their students in assessing themselves - that provide information to be used as feedback to modify teaching and learning activities. Such assessment becomes formative assessment when the evidence is actually used to adapt the teaching to meet student needs'. (p. 82). Formative assessment is broader than assessing a product or competence and giving feedback, as it involves feedback as one element together with activating students as resources for one another and as owners of their own learning (Black \& Wiliam, 2009; Dolin et al., 2017). In formative assessment students are involved in the whole assessment and feedback loop. They are involved in setting achievement goals, they produce work to be assessed and they are involved in assessing their own work. Dolin et al. (2017) emphasise the importance of the assessment being both criterion-referenced and student-referenced. Criterion-referenced assessment is based on external predetermined criteria and standards and is needed for students' (and teachers') feedback that points towards the goals of the course. Studentreferenced assessment is based on comparisons with the student's previous performance and expectations for this performance, and this is valuable for setting achievable goals with reference to Vygotsky's PZD. Assessments can be made by the teacher, other students (peer assessment) or the student themselves (ipsative assessment (Hughes, 2011). The student is also involved in deciding on the next steps in the learning process, and the next steps and next activities complete the feedback loop.

The competencies that can be developed through peer assessment are also worth considering. Topping (2010) points to the 'longer-term benefits with respect to transferable skills in communication and collaboration' (p. 395) as well as 'ancillary benefits in terms of the self-regulation of one's own learning' (p. 396). Boud and Soler (2015) use the term sustainable assessment to indicate assessment with a forward 
looking dimension that prepares students to meet their future learning needs, thus equipping students for judgement and decision-making beyond the timescale of a course. For PhD students this would help build their ability to judge their own work and that of others, goals that are often emphasized as objectives of PhD education; to become an independent or autonomous researcher (Tinkler \& Jackson, 2004). Both peer and self-assessment could be added as ILOs for the course to emphasise the importance for these competencies in PhD education and beyond.

\section{Intervention design}

To achieve the double goal of reducing teacher time and enhancing student learning an intervention was designed to introduce peer feedback on the PDP assignments through a number of steps. The identification and explication of assessment criteria is critical for students to engage in the assessment process, as outlined above. The steps in the intervention were:

1. Organising a meeting in the teaching team to explicate the criteria we use in giving feedback on PDPs.

2. Writing up the 'peer feedback criteria' and sharing with the teaching team. The peer feedback criteria should be written in a way that encourages course participants to ask questions that can help the author of the PDP to think further.

3. Testing the peer feedback criteria while giving feedback on PDPs (June 2016).

4. Instructing course participants at the following course to give feedback to two peers, so that each participant receives feedback from two others (September 2016).

5. Comparing the PDP assignments submitted with earlier assignments, to see if it is possible to judge whether the quality increases.

6. Constructing and distributing a questionnaire to get feedback from participants after the assignments have been approved, to learn how they perceived the peer feedback.

Based on these experiences the next iterations of the course were developed, with reference to the experiential learning cycle developed by Kolb (1984).

\section{Implementation}

Steps 1-3: Before this project started, the explication of criteria was mainly the responsibility of the teachers who shared old assessments and feedback with new teachers and through co-assessment of PDPs that required a second opinion. The core team of teachers discussed assessment criteria that we have (more or less tacitly) used when giving feedback. The criteria were written up and tested through 
teacher assessment and feedback in a course in June 2016, and they worked well for us as a reference. The criteria have been provided to course participants from September 2016.

\section{Designing peer feedback groups}

Step 4: Feedback groups in the September 2016 course were deliberately designed for internal variation based on our experience with assessing PDPs throughout the years. Although we did not make any systematic investigation of the reasons why students submitted thorough or inadequate PDPs, the teaching team had some insights based on face-to-face feedback sessions with participants in earlier versions of the course. Some participants have difficulties in grasping the idea of making a development plan as they are not used to working with the 'soft side' of their own development (being Scientists), or because cultural differences constitute a barrier to their understanding, especially understanding that they can set their own goals and steer the process rather than depending on the supervisor. Some also have language difficulties. Others do not find the exercise meaningful, or sense that their supervisors would not appreciate them spending time and effort on developing a PDP. Others again do not have the time, or do not prioritize the PDP over other tasks. Hence the parameters used for designing internally varied groups were mainly societal (national/educational) background, gender and level of participation during the first days of the course (engagement). It was assumed that these criteria would reflect the students' potential personal investment in the PDP. In the September course we ensured a high internal variation in the feedback groups based on national/educational background and gender.

\section{Technicalities of peer feedback in the Learning Management System}

Step 4: The Learning Management System (LMS, called CANVAS, https://www.canvaslms.com) has different options for peer feedback: the default option is a peer grading system and rubrics with a prescribed format for giving peer feedback that requires (enforces) peers to give feedback, so that each participant would give and get feedback from two others. This option is apparently based on ideas of controlling the behaviour of the participants do 'what they are supposed to', which actually goes against our aim of putting participants in charge of their PhD studies. The other option is to organize participants in groups and assign a sub-site for each group where they can upload and download documents as they wish. This was more in line with the kind of feature that we prefer, because it leaves the activities up to course participants to organize. It may take more work to get them to use the group space, and it may provide less scaffolding for the insecure participant because the system does not lead them through the process step-by-step, however, giving course participants their own space offers them the opportunity and experi- 
ence of organizing their peer feedback. The framework for self-determination developed by Ryan and Deci (2000) suggests that motivation can be supported through feeling competent, autonomous and relatedness. The default option of a peer grading system and rubrics leaves very little room for choosing methods, and no room for collaboration among group members. Hence, this approach would mean the course organizers would miss an opportunity to support autonomy and an opportunity for them to build collaboration among peers.

On the last day of the course and through an announcement in the LMS, course participants were instructed to upload assignments to their group sub-site folders and give each other feedback. They were given deadlines for the draft PDP for peer feedback, feedback criteria were available to them and a deadline for the final PDP to be submitted to the course teachers. The hope (and hypothesis) was that peer feedback would reduce the number of students who struggled with the assignment, and that ultimately this would reduce the amount of time that teachers needed to spend on feedback.

However, the submission process in the LMS was not 'foolproof' since the folder for the final PDP submission was also available, and many participants uploaded their draft PDP into this folder. Obviously, many participants had not found the group sub-sites.

\section{PDP assignments}

Step 5: The PDP assignments in the September course did not stand out as better than average. Four (out of 23) were asked to resubmit, at least three were inadequate, but were still acceptable, and around five were really good with substantive thinking reflected in the writing. The picture wasn't any better than the norm for the course when only one or two students are usually asked to resubmit. Thirteen participants had uploaded draft assignments into the folder for final assignments, including the four who were asked to resubmit. The activity in the group sub-sites reveals that five groups had engaged in peer feedback to a varying extent, but there is no clear trend towards a correlation between peer feedback and quality of assignment.

We gained further insights into possible effects of peer feedback by comparing the draft PDPs, the feedback provided and received and the final PDPs submitted. This comparison was carried out for eight participants. The conclusion from this comparison was that it was the students who actively engaged in giving feedback who used the feedback the most. Reading other group members' assignments also seemed to further inspire these students, as elements from one PDP assignment sometimes recurred in other PDP assignments within the same group. It was also noted that the feedback the students provide reveals a lot about their understanding of the task, 
and using the criteria for feedback does seem to scaffold the development of understanding for some students.

\section{PhD student experiences of peer assessment}

Step 6: I distributed a questionnaire to get the students' experience of how the peer assessment worked. I received eighteen responses to the questionnaire from the 23 participants. The responses indicate that peer feedback has potential, since half of the respondents found the peer feedback useful, both in terms of giving feedback, assessing other PDPs and receiving feedback.

Of the 18 respondents, $60 \%$ found it meaningful to give peer feedback while $17 \%$ found it difficult, and another $17 \%$ did not give peer feedback (two found the technicalities of the LMS to be a barrier and two were not confident that they could provide good feedback). Similarly, $60 \%$ found the feedback criteria helpful, while $27 \%$ found it difficult to use the criteria. Reviewing other PDPs seemed to help the vast majority.

Satisfaction with the feedback they received was slightly lower, in that $47 \%$ found the feedback useful. $18 \%$ felt they received praise that could support subsequent learning, another $12 \%$ did not find the feedback useful, and $18 \%$ did not get feedback. These experiences indicate that PhD students can benefit from being trained to give feedback and how to use assessment criteria during the course.

\section{Summary of findings}

Overall, this first iteration of using peer feedback in the Introduction course did not seem very successful in terms of higher quality assignments and less need for teacher feedback. Still, the analysis of the sample of assignments and peer feedback, and a questionnaire distributed to participants, indicate that peer feedback has the potential to support learning in the course. The following discussion focuses on the experiences from this first iteration in light of literature about formative assessment, and it strives to identify ways to make peer feedback more effective in the course.

\section{Discussion and next iterations of the course}

\section{Group formation}

The parameters we used for group formation are by and large supported by Topping (2010) who lists academic and social factors to consider when matching students, like year of study and academic ability, background experience in peer assessment (good or bad experiences) and culture and gender. We can be more explicit in matching participants with different background experience. This is most likely connected with educational and societal culture, which we very coarsely identify as nationality. It is, however, important not to make too rigid assumptions based on na- 
tionalities, but this was a pragmatic choice. In the future it would be interesting to combine this approach with a quick survey of the students on their experiences with peer feedback (good, bad, none). This could benefit the composition of the groups and student engagement in the activity. Another change to consider for future iterations of the course would be to create groups that are internally homogenous - that is the students in the groups have similar experiences and goals. It can be argued that this approach would enhance learning since the participants would (ideally) engage in discussions with others at similar levels, and not rely on the experienced peers to take control or just show the inexperienced members what to do next. However, in heterogenic groups they get the experience that they can help each other, and that will support their relational agency (Hopwood, 2010) and independence from teachers. Also, the use of homogenous groups would require teachers to support the inexperienced students, rather than stepping back and allowing the more experienced peers to do the support, so this approach is unlikely to reduce the number of hours that the teachers spend on the course.

\section{Integrating peer feedback in the course}

Boud and Molloy (2013) emphasise the importance of integrating peer feedback explicitly in the course, rather than using it as an add-on once the course is finished. In earlier iterations of the course we provided feedback to participants after the course, The idea was that the formatively intended feedback that for a long time was supported by face-to-face meetings after the course would support the PhD students in their further competence development. What we missed out with this approach was building the competence of self- and peer assessment or develop their judgement beyond the time frame of the course. The framework Boud and Molloy (2013) suggest for sustainable feedback is characterized by involving learners in dialogue and facilitating feedback processes to develop assessment capacities. This implies that feedback needs to be an integrated part of the course where course participants are trained in giving and using peer feedback. Such training is especially important for participants with limited or negative experiences with peer feedback, and as Topping (2010) mentions 'Students from different cultural background may be very different in acceptance of peer assessment' (p. 397).

The consequence of prioritizing the proximal zone of development, as noted earlier, is that not all students will get the same level of feedback. This contrasts with the summative exam situation where assessment is purely criterion-referenced (whether criteria are tacit and norm-based or explicit) and results have meanings for third parties. When the PDPs in the Introduction course are assessed, this information is then used for giving student-referenced feedback, so with the above in mind it is apparent that the reliability of the feedback across assignments is low. Higher reliability could be achieved if all course participants are assessed according to external 
criteria (criterion-referenced), which is important in exams where the grade matters for future careers (it allows future employers to judge competence levels). In the present format, the course aims to provide feedback that will help individual PhD students develop the competencies required to succeed in their studies The mixture of student-referenced and criterion-referenced feedback we use as teachers is continuously leveled out through comparison and discussion in the teacher team. Peers do not, however, have the opportunity to discuss and agree feedback, and therefore the feedback they provide may vary to a higher degree. Hence, reliability among peers' feedback may become an issue, and this makes it difficult to convince students that peer feedback is trustworthy (Topping, 2010). It is doubtful that peers can (or trust that they can) give the same type of feedback as the teachers, especially if they did not understand the task in the first place. When reading through the feedback that participants provide each other, some of this is at the level of our own feedback, while other feedback seems somewhat off track. The set-up with groups of three is a way to ensure that all course participants will get sufficient level and quality of feedback, and this makes it important to ensure that all participants engage in the peer feedback exercise. In practice some participants provided minimal feedback, although on the whole the majority of students did seem to understand and use the feedback criteria. But, there were two respondents to the questionnaire who stated that they did not give feedback because they were not confident that they could provide good feedback. The variation in the peer-feedback provided and the reluctance by some to engage in peer-feedback stresses the importance of training students how to give feedback and then allowing them to work with the criteria during the course to scaffold them in their practice, i.e. integrating feedback in the course, as Boud and Molloy (2013) suggest.

In the September 2016 course that trialed the peer-feedback approach, the feedback criteria were shared with course participants from the first day for guidance and transparency, in line with recommendations from literature (c.f. Gulikers, Bastiaens \& Kirschner, 2008). The aim was to guide the learning process and support the development of self-assessment capacities. However, the criteria were not actively incorporated into the teaching and learning activities, but in the 2017 course activities were included that enabled the participants to give criterion-referenced peer feedback on specific sections of the PDP that they worked with during the course. It also became apparent that it was important for the students to work in the group subsites in the LMS during contact time with teachers so that they became familiar with the technicalities. The questionnaire from the 2016 course revealed that two respondents said they did not give feedback because the technicalities of the LMS were a barrier. Limited wifi at the course centre was also a barrier to using the LMS more actively in previous iterations of the course. 
In the section about the implementation I discussed my reasoning for choosing the open group sub-sites for peer feedback, and avoiding the enforcement of the LMS system, making peer feedback required. However, enforcement and control will not support the PhD students in taking charge. However, enforcement as an extrinsic motivation may ensure that all the participants become experienced in giving feedback that their peers can use, and hence lead to personal engagement with the process and help them internalize the value of mutually giving and taking feedback. Another aspect of this refers to reliability; if some participants get limited or irrelevant feedback as a result of the peers not feeling adequately equipped to provide this kind of commentary, then rubrics may be a good support to ensure that everybody provides more substantial feedback. Another way forward is to work with the criteria and peer feedback during the course, and that is the path the course will follow in the future as it gives the students a chance to build useful competences for completing and enjoying the PhD study.

The first changes we implemented during 2017 included the integration of a session on feedback with the first session concerning the PDP (competence mapping) on the first day of the course, and the provision of time for the students to practice giving feedback to each other in all the PDP sessions. This has resulted in higher quality assignments. From all the assignments submitted from the four courses run in 2017 (91 in total) in only three cases were the students asked to resubmit. None of the assignments were considered shallow or inadequate, but all showed engagement with the topics. The reasons for resubmission were mainly of a technical nature rather than conceptual nature, and only one student had difficulties understanding a question. This is considerably better than before we introduced working with peer feedback during the course. This indicates that peer feedback does not work as an add-on, but only when integrated in the course, and this is what Boud and Molloy (2013) suggest, and what Nicol and Macfarlane-Dick (2006) describe as part of their principles for good feedback practice. If we assume that substantive and engaged assignments reflect better learning and an enhanced learning environment, then we did succeed in achieving this goal.

The other goal we had with introducing peer feedback was to cut the time teachers had to spend on giving feedback and so increase the financial sustainability of the course. This goal is linked to a variety of factors. In earlier versions of the course teachers inserted comments in assignments and the annotated documents were returned to the students by email. With the introduction of the LMS, teachers had access to a system called Speed-grader, which does not encourage long paragraphs of feedback. So, instead of writing comments in students' PDPs, when using the LMS teachers would write only the most important points in the Comments field in Speed-grader. Just using this function alone, offered the opportunity for teachers to reduce the time spent on feedback Secondly, the peer feedback influenced teachers' 
perceptions of how much time and effort should be spent on giving further feedback. Since the students already had feedback from their peers the teachers did not feel the same obligation to comment on every section of the PDPs. The third perspective is that it takes a longer time to give feedback on an assignment that is not very good. An example is an assignment by a student who has not understood one of the questions. One teacher faced with this situation wrote, 'I've asked [name] to resubmit, he had troubles identifying scientific/discipline skills and transferable [elements of the PDP], and supporting these with evidence. I spent a solid hour on his feedback. He's on the right track, but...' This comment emphasises the extra time teachers spend when assignments are of lower quality. All together, we have cut back on the time we send on giving feedback, and hence we did achieve that goal as well. Of course, it can then be discussed whether we have been giving too thorough feedback earlier, and whether the level of feedback we provide now is sufficient. Also the change of LMS at the same time as starting the peer feedback system makes results inconclusive with regards to time spent on feedback.

To sum up, the process of developing explicit criteria and testing these within the teaching team is a prerequisite for sharing clear criteria during the course. Comparing the assignments from the first cohort (September 2016) and then the following iterations of the course indicate that peer feedback needs to be an integral part of the course, so that course participants are trained in giving and receiving feedback and using the criteria. The improvement of assignments after integrating peer feedback reflects an enhanced learning environment where course participants learn from each other. The reduction in the number of assignments requiring improvement means that teachers spend less time on feedback- a personal estimate is that the time spent on feedback can be reduced from 40-60 minutes per assignment to 20-40 minutes per assignment.

The tentative conclusion is that it is possible to both increase financial sustainability and enhance the learning environment through the use of peer feedback on assignments, if formative feedback is taken a step further to formative assessment by making feedback criteria clear and shared, and making peer feedback an integral part of the course so that the feedback loop is complete and course participants are active partners in the feedback process.

Reservations to be observed are the effects of the change to a new LMS at the same time that peer feedback was introduced, and the awareness in teachers' minds that the feedback participants got from their peers makes it less critical for them to give comprehensive feedback. 


\section{Future development points}

In the future it would be beneficial to incorporate more of the seven principles for good feedback outlined by Nicol and Macfarlane-Dick (2006), for instance the involvement of course participants in defining the criteria, which would align with the course's emphasis on inductive approaches. However, if we also distribute our feedback criteria we need to consider when to share these criteria with them, and avoid that they get the feeling that we 'had the answers' but did not share them. This may be a matter of sufficient meta-communication.

Even when using feedback, there is a summative element to the assessment of assignments since the teachers judge whether the PDP meets the criteria to fulfill the quality assurance set out by the PhD school and the university. In this case, feedback for students who struggle may become less formative in the sense of supporting the students' PhD process beyond the course and perhaps become more target driven as it will outline what the students need to do to meet the pass criteria for the assignment. Although the feedback in principle is formative as it helps the individual to improve the assignment, the purpose of the process changes from being life-long learning to passing the course as the student needs the credits. Further research into this would entail an analysis of the feedback provided so far, and a comparison of those who pass with those who are asked to resubmit. It is important for such a study that the analysis is retrospective, since this possible bias has not been considered previously, and therefore not taken into consideration when writing feedback.

\section{References}

Althauser, R., \& Darnall, K. (2001). Enhancing critical reading and writing through peer reviews: An exploration of assisted performance. Teaching Sociology, 2335.

Black, P., \& Wiliam, D. (2009). Developing the theory of formative assessment. Educational Assessment, Evaluation and Accountability (formerly: Journal of Personnel Evaluation in Education), 21(1), 5-31.

Black, P., \& Wiliam, D. (2010). Inside the Black Box: Raising Standards through Classroom Assessment. Phi Delta Kappan, 92(1), 81-90.

Boud, D., \& Molloy, E. (2013). Rethinking models of feedback for learning: the challenge of design. Assessment \& Evaluation in Higher Education, 38(6), 698-712.

Boud, D., \& Soler, R. (2015). Sustainable assessment revisited. Assessment \& Evaluation in Higher Education, 1-14.

Cho, Y. H., \& Cho, K. (2011). Peer reviewers learn from giving comments. Instructional Science, 39(5), 629-643. 
Dolin, J. (2015). Teaching for Learning University Teaching and Learning (pp. 65-92). Frederiksberg, Denmark: Samfundslitteratur.

Dolin, J., Black, P., Harlen, W., \& Tiberghien, A. (2017). Exploring relations between formative and summative assessment. In J. Dolin \& R. H. Evans (Eds.), Transforming assessment - through an interplay between practice, research and policy (pp. 53-80). Cham, Switzerland: Springer.

Dysthe, O. (1995). Det flerstemmige klasserommet: skriving og samtale for å loere. Oslo: Ad Notam Gyldendal.

Edwards, A., \& D'arcy, C. (2004). Relational agency and disposition in sociocultural accounts of learning to teach. Educational Review, 56(2), 147-155.

Elbow, P., \& Belanoff, P. (1995). Sharing and responding. New York: McGraw-Hill.

Elliot, D. L., \& Kobayashi, S. (2017). Do PhD supervisors play a role in bridging academic cultures? Paper presented at the EARLI 17th Biennial Conference 2017: Education in the crossroads of economy and politics Tampere, Finland

Gulikers, J. T., Bastiaens, T. J., \& Kirschner, P. A. (2008). Defining authentic assessment. Five dimensions of authenticity. In A. Havnes \& L. McDowell (Eds.), Balancing dilemmas in assessment and learning in contemporary education (pp. 73-86). Oxon and New York: Routledge.

Harlen, W. (2013). Assessment \& inquiry-based science education: Issues in policy and practice: Global Network of Science Academies.

Hattie, J., \& Timperley, H. (2007). The power of feedback. Review of educational research, 77(1), 81-112.

Hopwood, N. (2010). A sociocultural view of doctoral students' relationships and agency. Studies in Continuing Education, 32(2), 103-117.

Hughes, G. (2011). Towards a personal best: a case for introducing ipsative assessment in higher education. Studies in Higher Education, 36(3), 353-367.

Kolb, D. A. (1984). Experiential learning: Experience as the source of learning and development (Vol. 1): Prentice-Hall Englewood Cliffs, NJ.

Li, L., Liu, X., \& Steckelberg, A. L. (2010). Assessor or assessee: How student learning improves by giving and receiving peer feedback. British Journal of Educational Technology, 41(3), 525-536.

Nicol, D. J., \& Macfarlane-Dick, D. (2006). Formative assessment and self-regulated learning: A model and seven principles of good feedback practice. Studies in Higher Education, 31(2), 199-218. 
Ryan, R. M., \& Deci, E. L. (2000). Intrinsic and extrinsic motivations: Classic definitions and new directions. Contemporary educational psychology, 25(1), 54-67.

Tinkler, P., \& Jackson, C. (2004). The doctoral examination process: A handbook for students, examiners and supervisors: A Handbook for Students, Examiners and Supervisors: McGraw-Hill Education (UK).

Topping, K. J. (2010). Peers as a source of formative assessment. In J. H. McMillan (Ed.), Handbook of formative assessment (pp. 395-412). Singapore: Sage.

Vygotsky, L. (1978). Interaction between learning and development. Readings on the development of children, 23(3), 34-41. 